Portland State University

PDXScholar

\title{
Screening for Candidate Genes Involved in Opioid Addiction in Reduced Complexity Cross Between B6J and B6NJ
}

Jeya Aishwarya Anandakumar

Portland State University

Follow this and additional works at: https://pdxscholar.library.pdx.edu/honorstheses

Part of the Biology Commons

Let us know how access to this document benefits you.

\section{Recommended Citation}

Anandakumar, Jeya Aishwarya, "Screening for Candidate Genes Involved in Opioid Addiction in Reduced Complexity Cross Between B6J and B6NJ" (2020). University Honors Theses. Paper 915.

https://doi.org/10.15760/honors.937

This Thesis is brought to you for free and open access. It has been accepted for inclusion in University Honors Theses by an authorized administrator of PDXScholar. Please contact us if we can make this document more accessible: pdxscholar@pdx.edu. 


\title{
Screening for Candidate Genes Involved in Opioid Addiction in Reduced \\ Complexity Cross Between B6J and B6NJ
}

\author{
by \\ Jeya Aishwarya Anandakumar \\ An undergraduate honors thesis submitted in partial fulfillment of the \\ requirements for the degree of Bachelor of Science in \\ University Honors and Biology
}

Thesis Adviser

Radhika Reddy, Ph.D.

Portland State University

2020 


\begin{abstract}
Drug overdose epidemic has worsened dramatically in the past 10 years. Opioid use disorder (OUD) is one of the biggest contributors to this rise. OUD has been a national public health and socioeconomic crisis. In 2017, the Center for Disease Control (CDC) has reported 47,600 opioid overdose deaths in the US alone. This amounts to $68 \%$ of all deaths due to drug overdose. Currently, 2.1 million Americans are suffering from OUD. The economic burden due to opioid misuse treatment was 171.7 billion US dollars in the year 2009 in the U.S. The projected cost in 2020 will be 280.5 billion US dollars. In the last two decades, with the precipitous increase (400\%) in opioid prescription as painkiller, death due to opioid misuse has also doubled. This necessitates an urgent need to develop alternative non-addictive drugs to treat chronic pain and also ways to minimize opioid use and misuse. Of several factors (intrinsic and extrinsic) influencing opioid addiction, genetic polymorphism plays a significant role in determining opioid addiction. Therefore, a better understanding of the genetic polymorphisms involved in opioid addiction will open up new avenues of opioid reversal treatments. In this study, having oxycodone as the representative drug of opioid category and locomotor behavior as the response attribute in a mice model, we looked at the expression level of 7 high priority candidate genes and identified 3 of them as target genes as their expression significantly increased on oxycodone administration and also induced locomotory behavior.
\end{abstract}

\title{
INTRODUCTION
}

Opioids are the most commonly used and effective analgesic treatment option for severe chronic pain (Corder et al., 2018) which include both natural (morphine and codeine), semisynthetic (oxycodone and hydrocodone) synthetic (fentanyl, methadone and tramadol) and 
illegal morphine derivative (heroin) compounds that interact with opioid neuroreceptors(Strain, 2016). Opioid receptors (mu, delta, kappa and nociceptin) belong to a seven transmembrane spanning G-protein coupled receptor superfamily activated both by the endogenous opioid proteins (endorphins, enkephalin, dynorphin, nociception) and exogenous opioids. Endogenous synthesis of opioids in the human body is involved in natural pain processing. Opioid receptors are also documented in the peripheral organs including heart and lungs(Wittert et al., 1996). Discovery of endogenous opioid peptides and receptors in parallel led to the synthesis of hyper-specific opioid drugs that have both beneficial and detrimental effects on the society as a whole (Corder et al., 2018). Exogenous opioids include both natural (morphine and codeine) and synthetics (fentanyl and methadone)(Morland, 2019). Opioid receptors are distributed both in the central and peripheral nervous systems. In the vertebrate brain, areas with high concentration of opioid receptors include the amygdala, nucleus accumbens, caudate putamen, and the ventral tegmentum area (Kalivas and Volkow, 2005). Opioid analgesics act on several cortical and subcortical sites (between the ventral tegmental area and nucleus accumbens) in the brain to influence dopaminergic neurotransmission and pain aversion (Hipólito et al., 2015). Notoriously all forms of opioids are known to induce tolerance, dependence and addiction(Satoh et al., 2000) and can lead to death related to overdose/misuse(National Institutes of Health, 2018). Though people in the US realized the dangers of opioids as early as in1914 (Herzberg et al., 2016), the problem of opioid crisis has long been a societal issue that has not been addressed completely. It is estimated that in the US, 90 deaths per day are from opioid overdose (Anon, 2017). The financial burden of opioid overdose/misuse is huge. The economic burden due to opioid misuse treatment was 171.7 billion US dollars in the year 2009 in the U.S. The projected cost in 2020 will be 280.5 billion US dollars (Morland, 2019). 
There has been a large increase in both prescription and non-prescription opioid use over the last decade. This has resulted in uncontrolled opioid overdose/abuse in the U.S. In addition, semi-synthetic opioids like oxycodone act like gateway drugs(Grau et al., 2007). Misuse of opioids ends up in heroin addiction among $80 \%$ of users. Oxycodone is a semi-synthetic opiate that is derived from Thebaine, a chemical found in opium(Ruan et al., 2017). It is a prescription opioid pain reliever that is the most commonly used in post-surgical pain management, pain related to cancer and chronic pain. Oxycodone while binding to the opioid receptors in the central and peripheral nervous systems to block pain signals also causes a burst of dopamine release resulting in an addictive feeling of pleasure and euphoria (Weele et al., 2015).

Opioid use disorder (OUD) is defined in the diagnostic and statistical manual V(DSM-V) of mental disorders (Anon, 2013) as a problematic pattern of opioid use leading to clinically significant impairment or distress (Live et al., 2019). Opioid dependence and addiction are manifestations of brain changes (structural and functional) that result from chronic opioid abuse(Ieong and Yuan, 2017). Defining a generalized treatment option to opioid addiction has been a riddle since individuals are differently susceptible to opioids (Dunn et al., 2019). Understanding the mechanisms underlying the individual differences in addiction like behavior is the key to develop personalized pharmacotherapy (George and Koob, 2017). The individual difference in addiction is the result of interaction of environmental influences as well as genetic predispositions that were different before the first use of opioids. These individual differences result in enhanced incidents of addiction in some individuals compared to others. Therefore, determining the association of genetic markers will help understand opioid addiction and improve identification of individuals at high risk of developing opioid addiction(Mistry et al., 2014). 
Hence, in the present study having oxycodone as the representative drug of opioid category and locomotor behavior as the response attribute in a mice model, I looked at the expression level of 7 high priority candidate genes and identified 3 of them as target genes of future exploration for their expression significantly increased on oxycodone administration and also resulted in enhanced locomotory behavior.

Understanding genetic link to addiction not only help proper treatment but also extend our knowledge on genetic variability behind opioid risk. Recent research has shown that genetic factors contribute to opioid addiction. Family and twin studies and individual gene studies are routinely involved addiction research. Familial OUD is investigated in families and their relatives with proband of opioid addiction (Merikangas et al., 1998). Twin studies have shown that the liability for opioid addiction risk is genetic in origin (Tsuang et al., 1998; Kendler et al., 2003). Candidate gene studies have also identified several putative genes of substance abuse. To mention

a few, dopamine receptors, opioid receptors, BDNF (brain derived neurotropic factor) and neurotropic factors (Bond et al., 1998; Dalley et al., 2007; Cui et al., 2011; Jia et al., 2011). Screening for more candidate genes with single nucleotide polymorphism that are involved in OUD will serve the objective defined in the beginning of the paragraph.

\section{MATERIALS AND METHODS}

Mice strains, B6J and B6NJ were used in the present study. A total of 160 mice comprising both sexes were used. Oxycodone used in the present study was purchased from Sigma-aldrich (St. Louis, MO). Mice were administered intraperitoneally with a dose of $1.25 \mathrm{mg} / \mathrm{kg}$ body weight oxycodone. Same volume of saline was administered to the control mice through the same route. 
Isogenic sub-strains provide a simplified system that can be used in the identification of individual contributions of genes to phenotypic traits. These isogenic sub-strains were developed through mating closely related sub-strains ( $\mathrm{C} 57 \mathrm{Bl} / 6 \mathrm{~J}$ and $\mathrm{B} 6 \mathrm{NJ})$, and then by crossing the resulting F1 progeny. This resulted in a reduced complexity F2 generation. The resulting F2 generation was backcrossed which resulted in the F2 recombinant strain. In the present study the substrains of C57B1/J6 and B6NJ mice were used.

Oxycodone exposure leads to various behavioral changes, and one of them includes age and dose dependent influence on locomotion(Rowe, 2008). The two mice B6J (6J) and B6NJ (NJ) mice were tested to observe any difference in their selected phenotypic (locomotion) behavior by using the multistage addiction assessment protocol (MAAP). The acute (locomotor, analgesia) addiction assessment was followed. The mice were given $1.25 \mathrm{mg} / \mathrm{kg}$ of oxycodone intraperitoneally. Control cohort were administered with equal volume of saline by the same route. One day after the drug administration, the locomotion behavior was tested in open field tracked by video recording. Total distance travelled per hour was digitally recorded. Testing were carried out using open field locomotor chamber equipped with laser photo beams and the acquired data were analyzed using Graphpad prism statistics software. $\mathrm{P}<0.05$ was considered statistically significant.

QTL analysis allows to link complex phenotype to specific regions of chromosomes. Expression QTL (eQTL) is a locus that explains a fraction of the genetic variance of a gene expression phenotype(Nica and Dermitzakis, 2013). eQTL mapping using genome wide association study (GWAS) allows the identification of novel gene loci (Nica and Dermitzakis, 2013). The objective of this process is to identify the action, interaction, number and precise 
location of the regions (Miles, C. \& Wayne, 2008). Genetic mapping helps to isolate genomic region containing the causal variants in reduced complexity cross(Bryant et al., 2018) obtained as explained earlier. eQTL analysis combined with the fine mapping of the reduced complexity cross resulted in the following candidate genes as high priority genes. The 9 high priority genes are Nuf2, Pcp4I1, Ncsrn, Atp1a2, Kcnj9, Igsf9, Cadm3, and Aim2. In present report we analyzed only seven genes excluding Nuf2 and Ncsrn.

Replication, transcription and translation is the central dogma of molecular biology. Translation generates the phenotypic variability by the expression of proteins that the genes coded for. Western blot analysis was used in the present study to determine the protein expression level in the striatal tissues of mice substrains. Routine Western blot analysis procedure with slight modification as explained in our previous publication was followed in the present study (Anandakumar et al., 2018). Total protein was extracted from the striatal tissue of brains from the

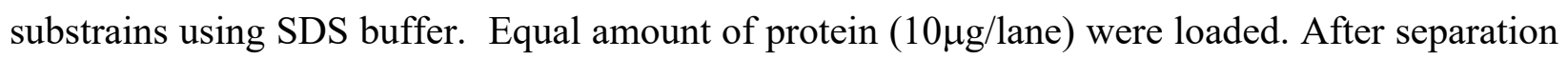
on denaturing gel, the proteins were probed with corresponding primary antibodies and labelled with HRP conjugated secondary antibodies. Protein bands were visualized using ECL reagent. Antibody against beta actin was used to normalize loading control. Protein expression level was expressed in arbitrary units determined as a ratio to the beta actin expression level. The intensity of the protein was measured through NIH imageJ software.

\section{RESULTS}

B6J and B6NJ cross and QTL analysis. Schematic showing the crosses between substrains is given in figure 1. The parental strains were crossed to create F1 individuals which were then 
crossed among themselves to produce F2 and crossed to one of the parent lines to create backcross progeny. Influence of oxycodone on locomotor behavior of mice strains is depicted in figure 2.2. Control cohort treated with saline did not show any effect in locomotor behavior of both $6 \mathrm{~J}$ and $\mathrm{NJ}$ substrains. Oxycodone at $1.25 \mathrm{mg} / \mathrm{kg}$ dose significantly decreased locomotor activity $(\mathrm{m} / \mathrm{h}) \mathrm{of}$ NJ substrain compared with $6 \mathrm{~J}$ substrain.

In the present study, we have estimated the protein expression level of ATP1a2, KCNJ9, AIM2, PCP411, RGS7, CADM3 and IGSF8 and the results are depicted in figures 3-9 respectively. ATP1a2 protein expression was significantly increased in the $\mathrm{NJ}$ substrain after the administration of oxycodone. On the other hand, KCNJ9 protein expression was significantly increased in the $6 \mathrm{~J}$ substrain. AIM2 protein expression was significantly decreased in $6 \mathrm{~J}$ substrain compared with NJ substrain. PCP411 did not show any significant difference in expression level between the substrains. RGS7 and CADM3 also did not show significant difference in the protein expression levels.

ATPla2 gene is involved in fine motor control in addition to focal epilepsy, hemiplegia, problems in cognition and behavior (Ueda et al., 2018). The gene on chromosome 1q23 encodes the $\alpha 2$ subunit of the sodium-potassium adenosine triphosphatase $\left(\mathrm{Na}^{+} / \mathrm{K}^{+}\right.$ATPase) pump. ATPla2 gene is involved in the maintenance of sodium and potassium ion gradients across the synaptic cleft and controls the glutamate reuptake by the glial cells(Rose et al., 2009). In the present study, we have found significantly increased expression of the gene in the NJ substrain compared with the $6 \mathrm{~J}$ substrain on oxycodone administration. The data are presented in figure 3 . 
$K C N J 9$ gene (a member of $K C N J$ genes) regulate the Kir2.xK ${ }^{+}$channel (Szuts et al., 2013). Several members of the $K C N J$ gene family encoding inward rectifying $\mathrm{K}+$ channels have been identified. They play role in $\mathrm{K}+$ homeostasis and contribute to the resting state membrane potential and $\mathrm{K}+$ recycling across the membrane. More than 90 different genes (including $K C N K, K C N J, K C N Q, K C N E$, and $S L O$ gene families)have been found to control $\mathrm{K}+$ channel activity in human genome (Hamilton and Devor, 2012). QTL mapping in mouse identified KCNJ9 as a genetic factor responsible for variation associated with analgesic effect of opioids(Smith et al., 2008). In the present study, we have determined significantly increased expression of KCNJ9 protein in the $6 \mathrm{~J}$ substrain compared to NJ strain and the data are depicted in figure 4.

Absent in melanoma 2 (AIM2) gene belong to the IFN-inducible HIN-200 domain containing protein family (Chen et al., 2006). It is a tumor suppressor and also play role in inflammasome to fight against pathogen invasion (Chen et al., 2017). AIM2 has also been involved in spatial memory, long-term potentiation and synaptic morphology (Chen et al., 2019). However, no previous reports are available on the differential expression level of AIM2 and opioid addiction phenotype. In the present study, we have determined significantly increased expression of AIM2 protein in NJ substrain compared with $6 \mathrm{~J}$ and the data are given in figure 5.

PCP4ll gene encodes a polypeptide with significant sequence similarity to purkinje cell protein (PCP) 4 and is expressed only in the central nervous system(Bulfone et al., 2004). PCP4l1 is associated with activity-dependent survival of the olfactory sensory neurons in mice to tune their olfactory sense to the environmental odor (Fischl et al., 2014). We have found no significant 
difference in the expression level of this gene with respect to exogenous opioid administration to $\mathrm{NJ}$ and $6 \mathrm{~J}$ substrains of mice. The data are given in figure 6.

Regulators of G protein signaling (RGS) gene is associated with G-protein coupled receptor signaling cascade and widely distributed in the nervous system. However, its physiological role has been only poorly understood. RGS7 is present in dendrites and involved in mGluR6/Ga/TRPM1 pathway(Shim et al., 2012). In the present report we found insignificant difference in the protein expression level between the two substrains of mice studied and the results are depicted in figure 7.

Axonal cell adhesion molecules belong to $C A D M 3$ gene family. Adhesion molecules are involved in axon schwann cell interaction and play vital role in the propagation of action potentials by saltatory conduction (Salzer et al., 2008). CADMs promote axo-glial interactions through CADM3 and other CADM associations (Kuschner, 2017). There was no significant difference in the CADM3 expression level between $\mathrm{NJ}$ and $6 \mathrm{~J}$ strains under opioid administration. The data are given in figure 8.

IGSF8 belongs to immunoglobulin superfamily proteins. The function of IGSF8 in the nervous system is not well understood. It has been documented in axon outgrowth and navigation (Maness and Schachner, 2007). In the present study, we have not found any significant difference in the expression level of IGSF8 protein between the substrains, NJ and $6 \mathrm{~J}$ and the data are given in figure 9. 


\section{DISCUSSION}

Opioids, including the prescription drug oxycodone are in general addictive substances. Opioid abuse has now reached epidemic proportion(Atluri et al., 2014). Though it has been generally accepted that addiction is a heritable trait, the genetic component determining OUD has not yet been dissected out (Kirkpatrick and Bryant, 2015). C57BL/6 inbred mouse substrains show differences in addiction-relevant locomotor behavior to opioids. In the present study, we have shown B6NJ substrain to have significantly decreased locomotor activity in response to oxycodone when compared to B6J substrain (figure 1). Difference in behavioral phenotype making it possible to map the underlying genetic factors (Kumar et al., 2013).

In the present study, we have selected the locomotion behavior as the phenotypic trait to test against the influence of exogenously administered oxycodone $(1.25 \mathrm{mg} / \mathrm{kg})$ in two substrains (NJ and 6J) of C57BL mouse line. When compared with the locomotion activity of control group the $6 \mathrm{~J}$ substrain showed significantly increased locomotor response than $\mathrm{NJ}$ substrain (figure 2.2). Based on the differential response to the same dose of oxycodone between the two substrains we sought to determine the expression level of some of the high priority genes determined by eQTL analysis. The following 9 genes were identified as high priority genes to OUD. However, due to time constraint only 7 of them were quantitative analyzed for their protein expression level using Western blot analysis. The following are the high priority genes selected for this study: ATP Ia2, AIM2, KCNJ9, PCP4l1, CADM3, RGS7, IGSF8, NUF2 and NCSRN. Except NUF2 and NCSRN, expression level of other proteins was determined. The NJ substrain showed significant increase in the protein expression of ATPa12 and AIM2 proteins, while the $6 \mathrm{~J}$ substrain showed significant increase in the expression of KCNJ9 protein. There was no significant difference in the expression 
level of PCP411, RGS7, CADM3 and IGSF8 proteins between the substrains on oxycodone administration.

ATPla2 gene is involved in fine motor control in addition to focal epilepsy, hemiplegia, problems in cognition and behavior (Ueda et al., 2018). The gene on chromosome 1q23 encodes the $\alpha 2$ subunit of the sodium-potassium adenosine triphosphatase $\left(\mathrm{Na}^{+} / \mathrm{K}^{+}\right.$ATPase $)$pump. ATPla2 gene is involved in the maintenance of sodium and potassium ion gradients across the synaptic cleft and controls the glutamate reuptake by the glial cells(Rose et al., 2009). In the present study, we have found significantly increased expression of the gene in the NJ substrain compared with the $6 \mathrm{~J}$ substrain on oxycodone administration. Heterozygous ATP1A2 mice has been reported to be hypoactive when compared to wild type(Moseley et al., 2003). However, in the present study, the $6 \mathrm{~J}$ substrain which showed hyperactivity to oxycodone administration expressed significantly lesser amount of ATPa12 protein when compared with NJ substrain which showed significantly lesser locomotor activity than 6J substrain (figure 1). However, both the strains were hyperactive to oxycodone when compared with saline control. In addition, we have not tested the difference in locomotor phenotype between wild type and $\mathrm{NJ}$ and $6 \mathrm{~J}$ substrains in the present study. The increased ATPA12 expression and decreased response to oxycodone (measured in terms of hypoactivity) shown by NJ substrain may denote its potential role in developing OUD(Gritz et al., 2016).

Absent in melanoma 2 (AIM2) gene belong to the IFN-inducible HIN-200 domain containing protein family (Chen et al., 2006). It is a tumor suppressor and also play role in inflammasome to fight against pathogen invasion (Chen et al., 2017). AIM2 has also been involved 
in spatial memory, long-term potentiation and synaptic morphology(Chen et al., 2019). However, no previous reports are available on the differential expression level of AIM2 and opioid addiction phenotype. In the present study, we have determined significantly increased expression of AIM2 protein in NJ substrain compared with $6 \mathrm{~J}$.

AIM2 gene is a cytosolic innate immune repressor that controls cell proliferation(Sharma et al., 2019). AIM2-like receptors are of importance to the immune system. However, they have been identified as contributing factors to several non-infectious neurological disorders, including alcoholism(Crews et al., 2017). In this study, it was shown that a greater expression of AIM2 makes NJ mice more responsive to oxycodone measured in terms of increased locomotor activity compared with $6 \mathrm{~J}$ substrain. This shows that AIM2 gene and AIM2-like receptors may also play a role in OUD, however, the statement needs further corroborative investigation.

$K C N J 9$ gene (a member of $K C N J$ genes) regulate the $\mathrm{Kir} 2 \cdot \mathrm{xK}^{+}$channel (Szuts et al., 2013). Several members of the $K C N J$ gene family encoding inward rectifying $\mathrm{K}+$ channels have been identified. They play role in $\mathrm{K}+$ homeostasis and contribute to the resting state membrane potential and $\mathrm{K}+$ recycling across the membrane. More than 90 different genes (including $K C N K, K C N J, K C N Q, K C N E$, and $S L O$ gene families)have been found to control $\mathrm{K}+$ channel activity in human genome (Hamilton and Devor, 2012). QTL mapping in mouse identified KCNJ9 as a genetic factor responsible for variation associated with analgesic effect of opioids(Smith et al., 2008). In the present study, we have determined significantly increased expression of KCNJ9 protein in the $6 \mathrm{~J}$ substrain compared to NJ strain (figure 4). Previous study showed KCNJ9 knockout mice exhibit higher locomotion under the influence of alcohol compared to wildtype. The results of this study are in corroboration with the previous findings. B6NJ mice expressed 
lower levels of KCNJ9 and were more impacted by the oxycodone than its counterpart B6J. In this study, it was shown that a lower expression of this gene, KCNJ9, makes B6NJ mice more suspectable to oxycodone induced locomotor behaviors.

\section{CONCLUSION}

The two substrains $\mathrm{NJ}$ and $6 \mathrm{~J}$ showed differential response to the same dose of oxycodone measured in terms of locomotor behavior. Both the two substrains were responsive to oxycodone when compared with the saline administered control cohort. However, NJ substrain showed significantly lesser locomotor response in relation to $6 \mathrm{~J}$ substrain. NJ substrain showed increased expression of ATP1A2 and AIM2 protein level while $6 \mathrm{~J}$ showed increased expression of KCNJ9 protein. Both the two strains did not show any difference in the protein expression pattern with respect to PCP4L1, RGS7, CADM3 and IGSF8 proteins.

\section{FUTURE DIRECTIONS}

Future studies will be focused to study the basal and opioid-induced endogenous opioid levels which will serve as an index of neurochemical mechanisms underlying the differential behavioral phenotype. Further, the downstream signaling mechanisms of the gene product studied in the present report will be worth exploring. For example, even though, we did not find difference in the expression level of RGS7, we have not explored other associated proteins like G $\beta 5$ which is involved in the stabilization of RGS7. Also, the other two high priority genes NUF2 and NCSRN will also be focused in our future studies. 


\section{FUNDING}

This study was funded in part by the grants R01DA039168, R00DA029635, R03DA038287 and R21DA038738 (CDB).

\section{ACKNOWLEDGEMENT}

I would like to thank Dr. Camron D. Bryant, Associate Professor and Principal Investigator, Laboratory of Addiction Genetics, Boston University School of Medicine, Boston for financial support and permission to carry out this piece of research in his lab. I also record my sincere thanks to Dr. Jacob Beierle for mentoring and Dr. Radhika Reddy for her guidance and supervision.

\section{REFERENCES}

Anandakumar J, Mills KL, Earl EA, Irwin L, Miranda-Dominguez O, Demeter D V., WaltonWeston A, Karalunas S, Nigg J, Fair DA (2018) Individual differences in functional brain connectivity predict temporal discounting preference in the transition to adolescence. Dev Cogn Neurosci.

Anon (2013) Diagnostic and Statistical Manual of Mental Disorders, 5th Edition.

Anon (2017) Pain Management and the Opioid Epidemic.

Atluri S, Sudarshan G, Manchikanti L (2014) Assessment of the trends in medical use and misuse of opioid analgesics from 2004 to 2011. Pain Physician.

Bond C, Laforge KS, Tian M, Melia D, Zhang S, Borg L, Gong J, Schluger J, Strong JA, Leal SM, Tischfield JA, Kreek MJ, Yu L (1998) Single-nucleotide polymorphism in the human mu opioid receptor gene alters $\beta$-endorphin binding and activity: Possible implications for opiate addiction. Proc Natl Acad Sci U S A.

Bryant CD, Ferris MT, Villena FPMD, Imad Damaj M, Kumar V, Mulligan MK (2018) Reduced complexity cross design for behavioral genetics. In: Molecular-Genetic and Statistical Techniques for Behavioral and Neural Research.

Bulfone A, Caccioppoli C, Pardini C, Faedo A, Martinez S, Banfi S (2004) Pcp4l1, a novel gene encoding a Pcp4-like polypeptide, is expressed in specific domains of the developing brain. Gene Expr Patterns.

Chen IF, Ou-Yang F, Hung JY, Liu JC, Wang H, Wang SC, Hou MF, Hortobagyi GN, Hung MC (2006) AIM2 suppresses human breast cancer cell proliferation in vitro and mammary tumor growth in a mouse model. Mol Cancer Ther.

Chen J, Shu S, Chen Y, Liu Z, Yu L, Yang L, Xu Y, Zhang M (2019) AIM2 deletion promotes neuroplasticity and spatial memory of mice. Brain Res Bull.

Chen J, Wang Z, Yu S (2017) AIM2 regulates viability and apoptosis in human colorectal cancer cells via the Pi3k/Akt pathway. Onco Targets Ther. 
Corder G, Castro DC, Bruchas MR, Scherrer G (2018) Endogenous and Exogenous Opioids in Pain HHS Public Access. Annu Rev Neurosci 41:453-473 Available at: https://www.ncbi.nlm.nih.gov/pmc/articles/PMC6428583/pdf/nihms-1013459.pdf.

Crews FT, Walter TJ, Coleman LG, Vetreno RP (2017) Toll-like receptor signaling and stages of addiction. Psychopharmacology (Berl).

Cui D, Zhang H, Yang BZ, Listman JB, Li D, Price LH, Carpenter LL, Tyrka AR, Anton RF, Kranzler HR, Gelernter J (2011) Variation in NGFB is associated with primary affective disorders in women. Am J Med Genet Part B Neuropsychiatr Genet.

Dalley JW, Fryer TD, Brichard L, Robinson ESJ, Theobald DEH, Lääne K, Peña Y, Murphy ER, Shah Y, Probst K, Abakumova I, Aigbirhio FI, Richards HK, Hong Y, Baron JC, Everitt BJ, Robbins TW (2007) Nucleus accumbens D2/3 receptors predict trait impulsivity and cocaine reinforcement. Science (80- ).

Dunn KE, Barrett FS, Brands B, Marsh DC, Bigelow GE (2019) Individual differences in human opioid abuse potential as observed in a human laboratory study. Drug Alcohol Depend.

Fischl AM, Heron PM, Stromberg AJ, McClintock TS (2014) Activity-dependent genes in mouse olfactory sensory neurons. Chem Senses.

George O, Koob GF (2017) Individual differences in the neuropsychopathology of addiction. Dialogues Clin Neurosci 19:217-229.

Grau LE, Dasgupta N, Harvey AP, Irwin K, Givens A, Kinzly ML, Heimer R (2007) Illicit use of opioids: Is OxyContin ${ }^{\circledR}$ a "gateway drug"? Am J Addict 16:166-173.

Gritz SM, Larson C, Radcliffe RA (2016) Atp1a2 contributes modestly to alcohol-related behaviors. Alcohol 56:29-37.

Hamilton KL, Devor DC (2012) Basolateral membrane K + channels in renal epithelial cells. Am J Physiol - Ren Physiol.

Herzberg D, Guarino H, Mateu-Gelabert P, Bennett AS (2016) Recurring epidemics of pharmaceutical drug abuse in America: Time for an all-drug strategy. Am J Public Health.

Hipólito L, Wilson-Poe A, Campos-Jurado Y, Zhong E, Gonzalez-Romero J, Virag L, Whittington R, Comer SD, Carlton SM, Walker BM, Bruchas MR, Morón JA (2015) Inflammatory pain promotes increased opioid self-administration: Role of dysregulated ventral tegmental area $\mu$ opioid receptors. J Neurosci.

Ieong HFH, Yuan Z (2017) Resting-state neuroimaging and neuropsychological findings in opioid use disorder during abstinence: A review. Front Hum Neurosci 11.

Jia W, Shi JG, Wu B, Ao L, Zhang R, Zhu YS (2011) Polymorphisms of brain-derived neurotrophic factor associated with heroin dependence. Neurosci Lett.

Kalivas PW, Volkow ND (2005) The neural basis of addiction: A pathology of motivation and choice. Am J Psychiatry.

Kendler KS, Jacobson KC, Prescott CA, Neale MC (2003) Specificity of genetic and environmental risk factors for use and abuse/dependence of cannabis, cocaine, hallucinogens, sedatives, stimulants, and opiates in male twins. Am J Psychiatry.

Kirkpatrick SL, Bryant CD (2015) Behavioral architecture of opioid reward and aversion in C57BL/6 substrains. Front Behav Neurosci 8:1-11.

Kumar V, Kim K, Joseph C, Kourrich S, Yoo SH, Huang HC, Vitaterna MH, De Villena FPM, Churchill G, Bonci A, Takahashi JS (2013) C57BL/6N mutation in cytoplasmic FMRP interacting protein 2 regulates cocaine response. Science (80-).

Kuschner (2017) 乳鼠心肌提取 HHS Public Access. Physiol Behav 176:139-148.

Maness PF, Schachner M (2007) Neural recognition molecules of the immunoglobulin 
superfamily: Signaling transducers of axon guidance and neuronal migration. Nat Neurosci.

Merikangas KR, Stolar M, Stevens DE, Goulet J, Preisig MA, Fenton B, Zhang H, O'Malley SS, Rounsaville BJ (1998) Familial transmission of substance use disorders. Arch Gen Psychiatry.

Miles, C. \& Wayne M (2008) Quantitative Trait Locus (QTL) Analysis. Nat Educ.

Mistry C, Bawor M, Desai D, Marsh D, Samaan Z (2014) Genetics of Opioid Dependence: A Review of the Genetic Contribution to Opioid Dependence. Curr Psychiatry Rev.

Morland R (2019) Evolution of the national opioid crisis. Nursing (Lond) 49:51-56.

Moseley AE, Lieske SP, Wetzel RK, James PF, He S, Shelly DA, Paul RJ, Boivin GP, Witte DP, Ramirez JM, Sweadner KJ, Lingrel JB (2003) The Na,K-ATPase $\alpha 2$ isoform is expressed in neurons, and its absence disrupts neuronal activity in newborn mice. J Biol Chem.

National Institutes of Health NI on DA (2018) Opioid Overdose Crisis. Natl Inst Drug Abus Adv Addict Sci.

Nica AC, Dermitzakis ET (2013) Expression quantitative trait loci: Present and future. Philos Trans R Soc B Biol Sci 368.

Rose EM, Koo JCP, Antflick JE, Ahmed SM, Angers S, Hampson DR (2009) Glutamate transporter coupling to Na,K-ATPase. J Neurosci.

Rowe (2008) 基因的改变NIH Public Access. Bone 23:1-7 Available at: https://www.ncbi.nlm.nih.gov/pmc/articles/PMC3624763/pdf/nihms412728.pdf.

Ruan X, Mancuso KF, Kaye AD (2017) Revisiting Oxycodone Analgesia: A Review and Hypothesis. Anesthesiol Clin 35:e163-e174 Available at: http://dx.doi.org/10.1016/j.anclin.2017.01.022.

Salzer JL, Brophy PJ, Peles E (2008) Molecular domains of myelinated axons in the peripheral nervous system. Glia.

Satoh M, Seki T, Minami M (2000) Opioid receptors. Tanpakushitsu Kakusan Koso 45:985-990.

Sharma BR, Karki R, Kanneganti TD (2019) Role of AIM2 inflammasome in inflammatory diseases, cancer and infection. Eur J Immunol.

Shim H, Wang CT, Chen YL, Chau VQ, Fu KG, Yang J, McQuiston AR, Fisher RA, Chen CK (2012) Defective retinal depolarizing bipolar cells in regulators of $\mathrm{G}$ protein signaling (RGS) 7 and 11 double null mice. J Biol Chem 287:14873-14879.

Smith SB, Marker CL, Perry C, Liao G, Sotocinal SG, Austin JS, Melmed K, David Clark J, Peltz G, Wickman K, Mogil JS (2008) Quantitative trait locus and computational mapping identifies Kcnj9 (GIRK3) as a candidate gene affecting analgesia from multiple drug classes. Pharmacogenet Genomics.

Strain E (2016) Opioid use disorder: epidemiology, pharmacology, clinical manifestations, course, screening, assessment, and diagnosis. UpToDate.

Szuts V et al. (2013) Altered expression of genes for kir ion channels in dilated cardiomyopathy. Can J Physiol Pharmacol.

Tsuang MT, Lyons MJ, Meyer JM, Doyle T, Eisen SA, Goldberg J, True W, Lin N, Toomey R, Eaves L (1998) Co-occurrence of Abuse of Different Drugs in Men. Arch Gen Psychiatry.

Ueda K, Serajee F, Huq AM (2018) Clinical benefit of NMDA receptor antagonists in a patient with ATP1A2 gene mutation. Pediatrics.

Weele CM Vander, Porter-stransky KA, Mabrouk OS (2015) Rapid Dopamine Transmission Within the Nucleus Accumbens Dramatically Differs Following. 40:3041-3054.

Wittert G, Hope P, Pyle D (1996) Tissue distribution of opioid receptor gene expression in the rat. Biochem Biophys Res Commun 218:877-881. 


\section{LIST OF TABLES}

Table 1. High priority Genes. Results of eQTL analysis was performed on genes in distal chromosome 1 to identify the high priority genes. High priority genes are shown within the red box and highlighted in blue.

\section{FIGURE LEGEND}

Figure 1. B6J and B6NJ cross and QTL analysis. A) Schematic showing the crosses between substrains. B). The parental strains were crossed to create F1 individuals which were then crossed among themselves to produce $\mathrm{F} 2$ and crossed to one of the parent lines to create backcross progeny.

Figure 2. Influence of oxycodone on locomotor behavior of mice strains. Control cohort treated with saline did not show any effect in locomotor behavior of both $6 \mathrm{~J}$ and $\mathrm{NJ}$ substrains. Oxycodone at $1.25 \mathrm{mg} / \mathrm{kg}$ dose significantly decreased locomotor activity $(\mathrm{m} / \mathrm{h})$ of $\mathrm{NJ}$ substrain compared with $6 \mathrm{~J}$ substrain.

Figure 3. Protein expression level of ATP1a2. Equal quantity of striatal protein from NJ and $6 \mathrm{~J}$ strains was loaded on to 12 wells as indicated in the figure. Intensity of the protein bands were measured with NIH ImageJ software. NJ substrain showed significantly $(\mathrm{P}=0.0001)$ increased expression of ATP1a2 protein compared to $6 \mathrm{~J}$ substrain.

Figure 4. Protein expression level of KCNJ9. Equal quantity of striatal protein from NJ and $6 \mathrm{~J}$ strains was loaded on to 12 wells as indicated in the figure. Intensity of the protein bands were measured with NIH ImageJ software. $6 \mathrm{~J}$ substrain showed significantly $(P=0.04)$ increased expression of KCNJ9 protein compared to NJ substrain. 
Figure 5. Protein expression level of AIM2. Equal quantity of striatal protein from NJ and 6J strains was loaded on to 12 wells as indicated in the figure. Intensity of the protein bands were measured with NIH ImageJ software. NJ substrain showed significantly $(P=0.003)$ increased expression of AIM2 protein compared to $6 \mathrm{~J}$ substrain.

Figure 6. Protein expression level of PCP411. Equal quantity of striatal protein from NJ and 6J strains was loaded on to 12 wells as indicated in the figure. Intensity of the protein bands were measured with NIH ImageJ software. There was no significant difference in the protein expression level between the substrains $(\mathrm{P}=0.181)$.

Figure 7. Protein expression level of RGST. Equal quantity of striatal protein from NJ and $6 \mathrm{~J}$ strains was loaded on to 12 wells as indicated in the figure. Intensity of the protein bands were measured with NIH ImageJ software. There was no significant difference in the protein expression level between the substrains $(\mathrm{P}=0.088)$.

Figure 8. Protein expression level of CADM3. Equal quantity of striatal protein from NJ and $6 \mathrm{~J}$ strains was loaded on to 12 wells as indicated in the figure. Intensity of the protein bands were measured with NIH ImageJ software. There was no significant difference in the protein expression level between the substrains $(\mathrm{P}=0.162)$.

Figure 9. Protein expression level of IGSF8. Equal quantity of striatal protein from NJ and 6J strains was loaded on to 12 wells as indicated in the figure. Intensity of the protein bands were 
measured with NIH ImageJ software. There was no significant difference in the protein expression

level between the substrains $(\mathrm{P}=0.329)$.

\section{TABLE 1}

\begin{tabular}{|c|c|c|c|c|c|c|c|c|c|c|c|c|c|}
\hline eQTL gene & Gene Name & chr & Mb & SNP (Mb) & Exp. & P. Assoc. & Adj.P SNPs & Reg. D2 & , D2 & Reg. D4 & r,D4 & Reg. EPM & r, EPM \\
\hline Gpr161 & G protein-coupled receptor 161 & $\overline{1}$ & 165.3 & 181.3 & 3.5 & $1.4 \mathrm{E}-03$ & $1.7 \mathrm{E}-02 \mathrm{no}$ & & & & - & 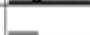 & \\
\hline Pou2t1 & POU domain, class 2, transcription factor 1 & 1 & 165.9 & 181.3 & 5.37 & 2.2E-06 & $1.4 \mathrm{E}-04 \mathrm{no}$ & $9.9 E-03$ & & & & & \\
\hline IId 2 & immunoglobulin-like domain containing receptor 2 & 1 & 166.3 & 181.3 & 6.66 & $7.0 E-04$ & $1.0 \mathrm{E}-02 \mathrm{no}$ & 4.2E-04 & 0.42 & $3.4 E-02$ & & 1.1.E-07 & 0.55 \\
\hline Nu12 & NUF2, NDC80 kinetochore complex component & 1 & 169.5 & 181.3 & 1.53 & $3.2 E-03$ & $3.1 \mathrm{E}-02 \mathrm{no}$ & & & & & & \\
\hline Pcp411 & Purkinje cell protein 4 -like 1 & 1 & 171.2 & 181.3 & 8.64 & 4.2E-06 & 2.3E-04 no & $5.3 \mathrm{E}-09$ & -0.53 & $3.4 \mathrm{E}-07$ & -0.48 & $1.6 \mathrm{E}-08$ & -0.55 \\
\hline Nestn & nicastrin & 1 & 172.1 & 181.3 & 5.72 & $6.8 \mathrm{E}-04$ & $1.0 \mathrm{E}-02 \mathrm{no}$ & & & & & & \\
\hline Atp1a2 & t transporting, alpha 2 polypeptide & 1 & 172.3 & 181.3 & 9.74 & 9.6E-05 & $2.3 \mathrm{E}-03 \mathrm{no}$ & 2.2E-05 & 0.37 & $3.5 \mathrm{E}-07$ & 0.45 & $1.0 \mathrm{E}-02$ & \\
\hline Kcnj9 & $\mathrm{K}+$ inwardly-rectifying channel, subfamily J, member 9 & 1 & 172.3 & 181.3 & 6.74 & 1.1.E-03 & $1.4 \mathrm{E}-02 \mathrm{no}$ & $3.9 \mathrm{E}-03$ & & & & 4.2E-04 & 0.44 \\
\hline Igsf9 & immunoglobulin superfamily, member 9 & 1 & 172.5 & 181.3 & 3.78 & 2.4E-03 & $2.5 \mathrm{E}-02 \mathrm{no}$ & 3.5E-04 & -0.48 & $9.5 \mathrm{E}-04$ & -0.46 & $6.9 E-04$ & -0.46 \\
\hline Cadm3 & cell adhesion molecule 3 & 1 & 173.3 & 181.3 & 8.63 & 2.1E-05 & $7.5 \mathrm{E}-04$ yes & & & & & $2.5 E-02$ & \\
\hline Aim2 & absent in melanoma 2 & 1 & 173.4 & 181.3 & 1.84 & $2.0 \mathrm{E}-03$ & $2.2 E-02$ ves & & & & & & \\
\hline Rgs7 & Regulator of g-protein signaling 7 & 1 & 175.5 & 181.3 & 4.93 & $1.5 \mathrm{E}-03$ & $1.8 \mathrm{E}-02$ yes & $1.4 E-02$ & 0.58 & & 0.35 & $1.5 \mathrm{E}-02$ & \\
\hline
\end{tabular}




\section{FIGURES}

Figure 1

A
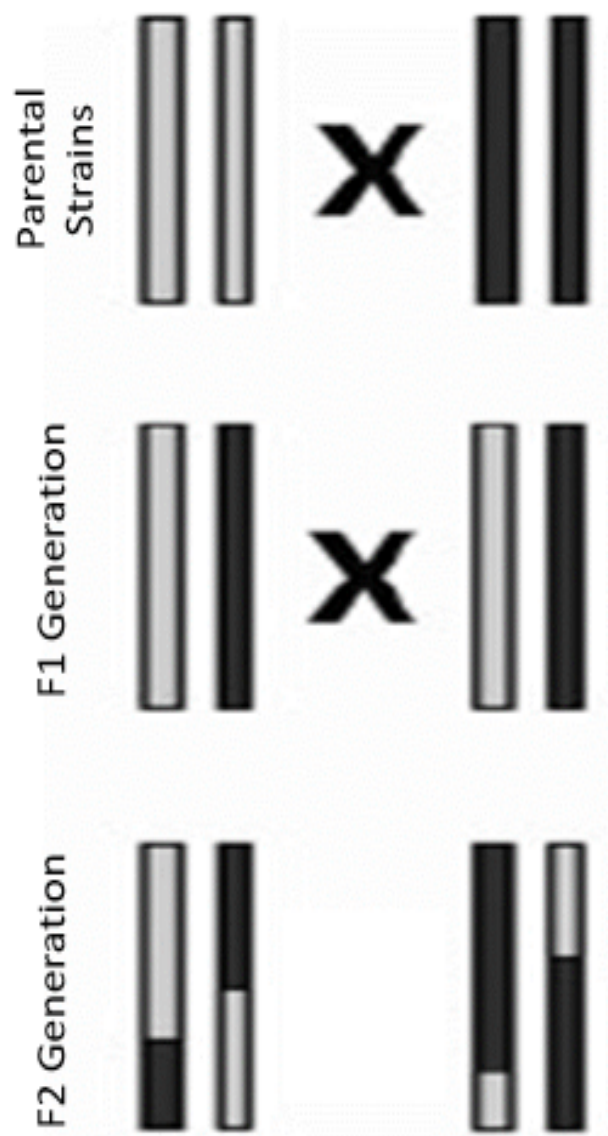

B
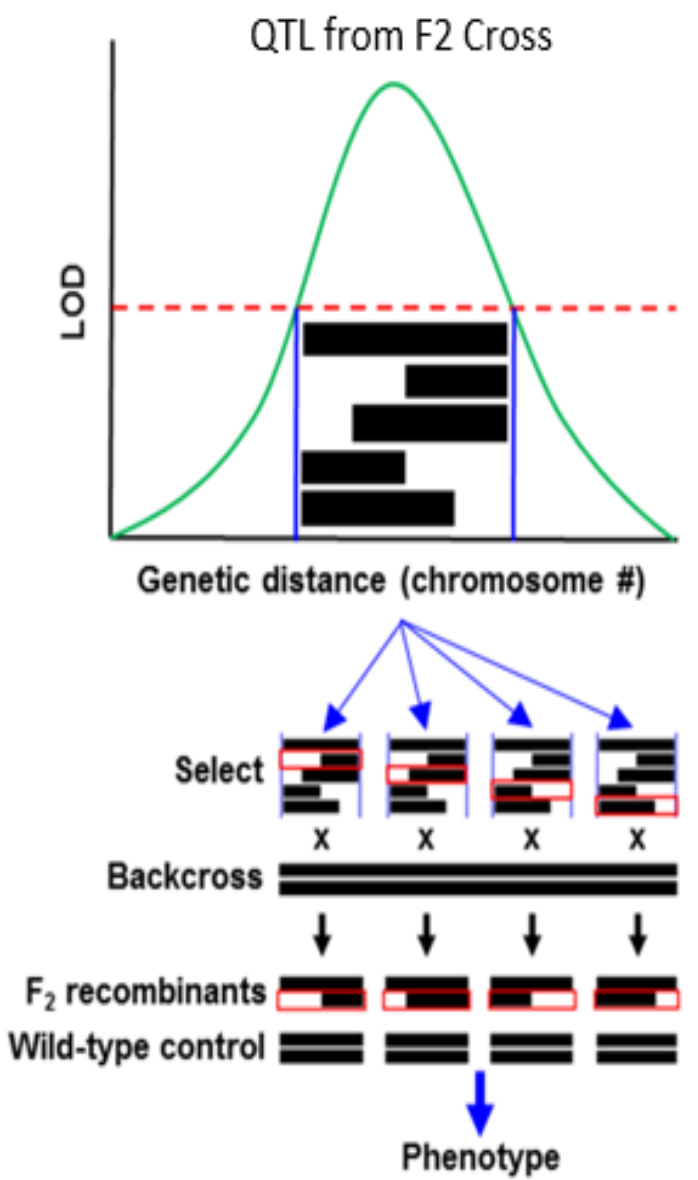
Figure 2

\section{LOCOMOTOR ACTIVITY}

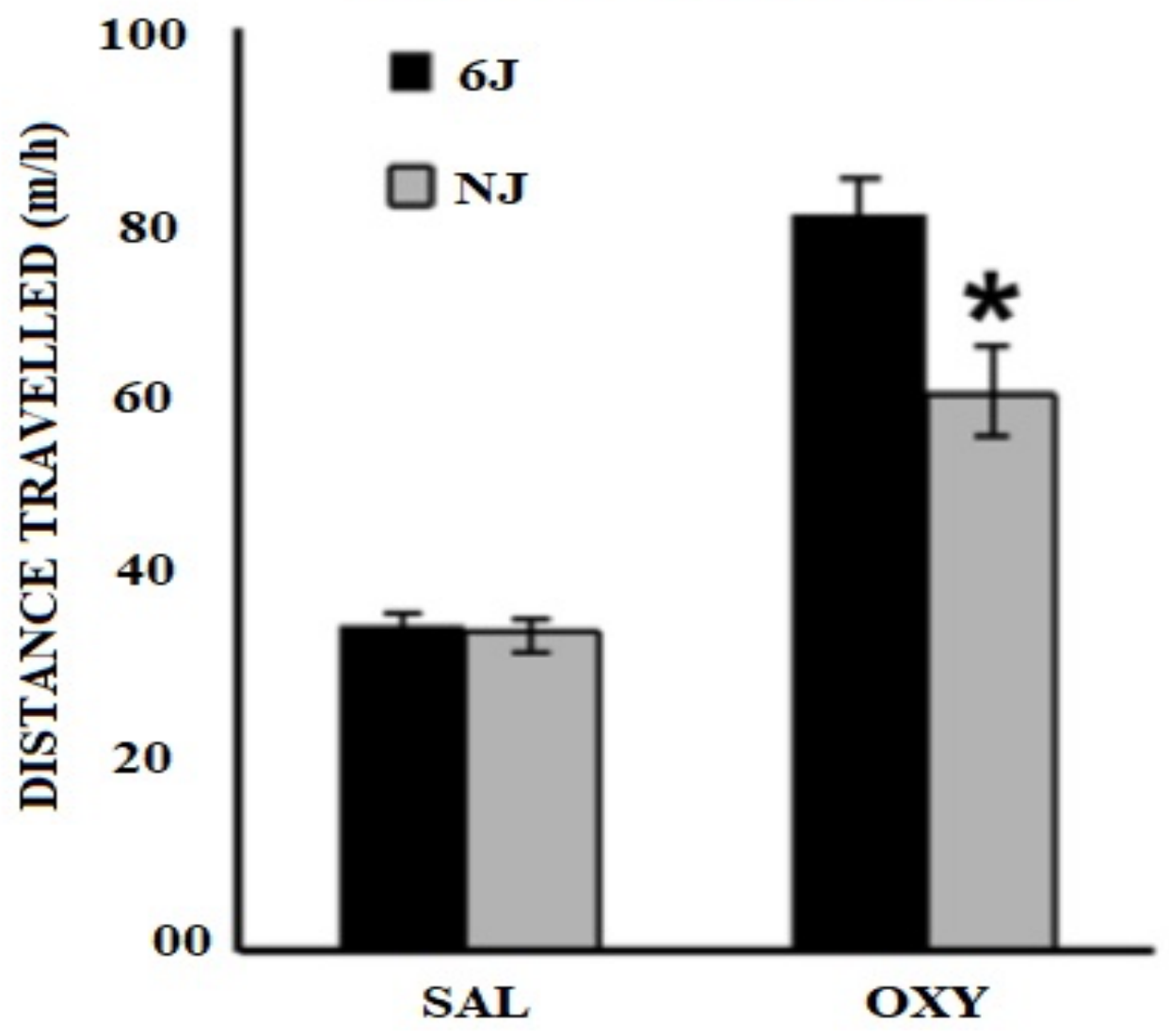


Figure 3

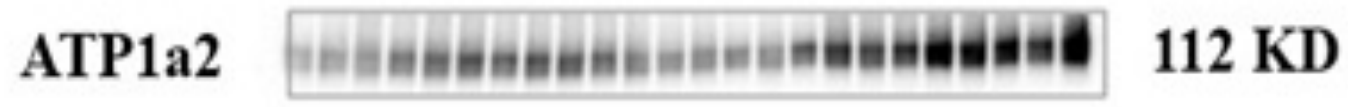

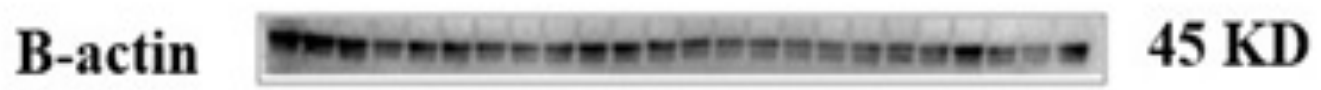

ATPasela2 Protein Expression

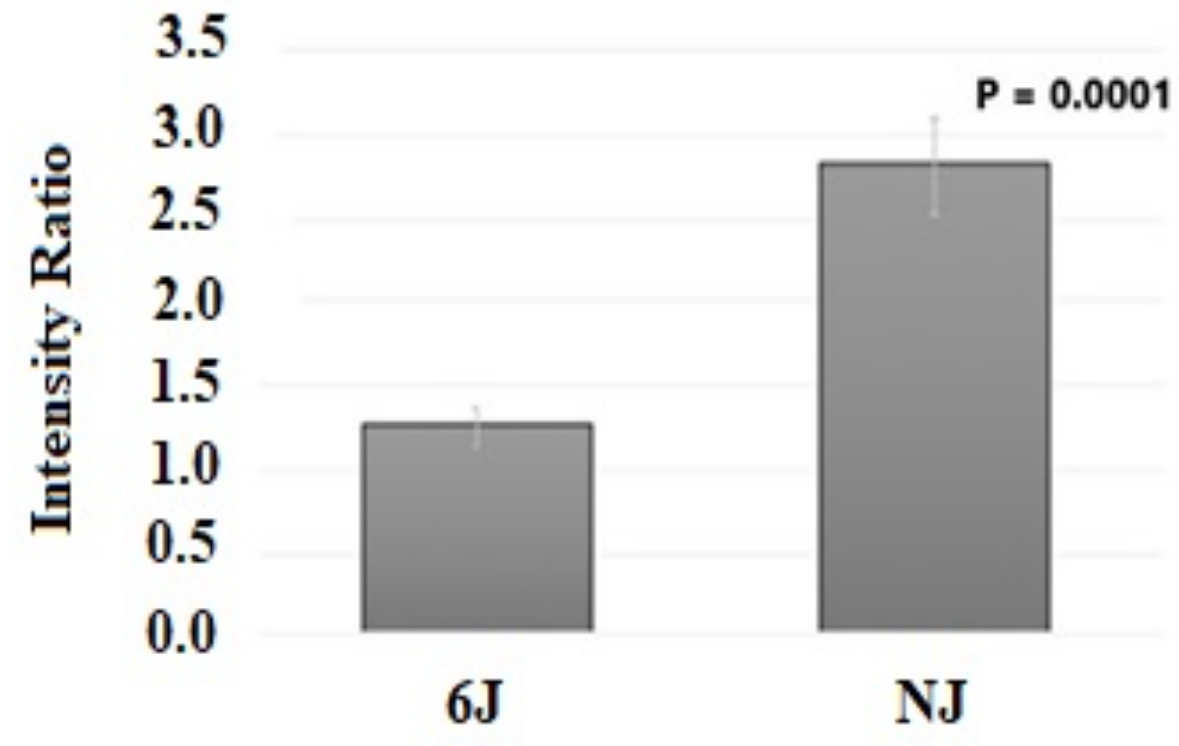


Figure 4

KCNJ9

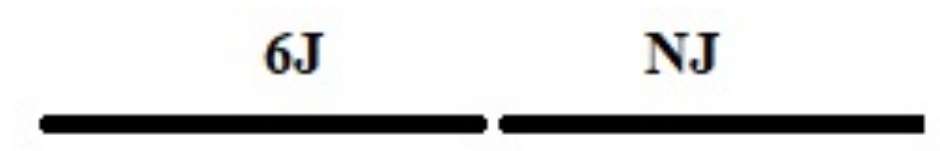

B-Actin

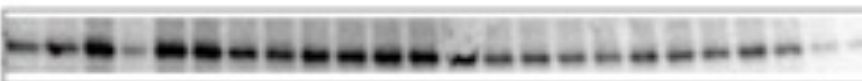

$44 \mathrm{KD}$

$45 \mathrm{KD}$

KCNJ9 Protein Expression
ㅇ.2
乲 1.0
. 0.6
音 0.4
0.0

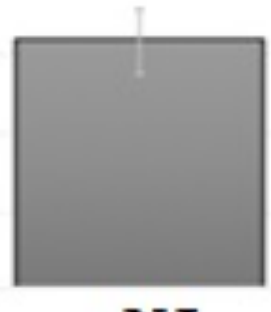

NJ

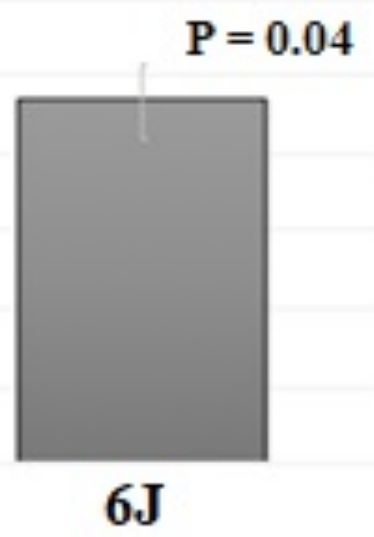


Figure 5

NJ

6J

AIM2 HeffHen $39 \mathrm{KD}$

B-Actin - - $45 \mathrm{KD}$

AIM2 Protein Expression

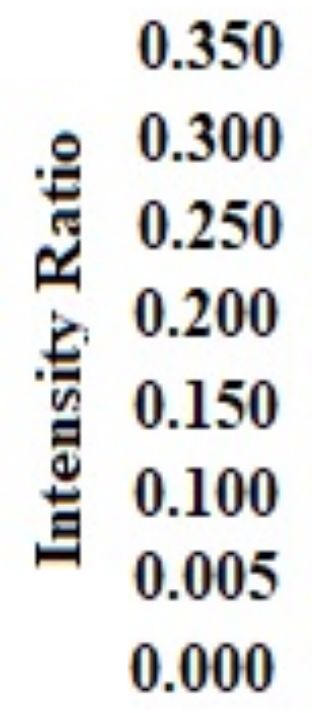

$$
P=0.0032
$$

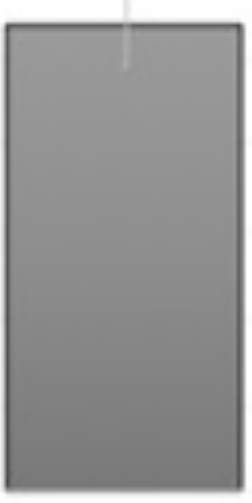

NJ

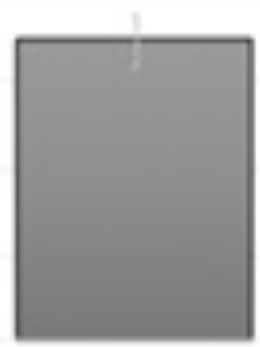

6J 
Figure 6
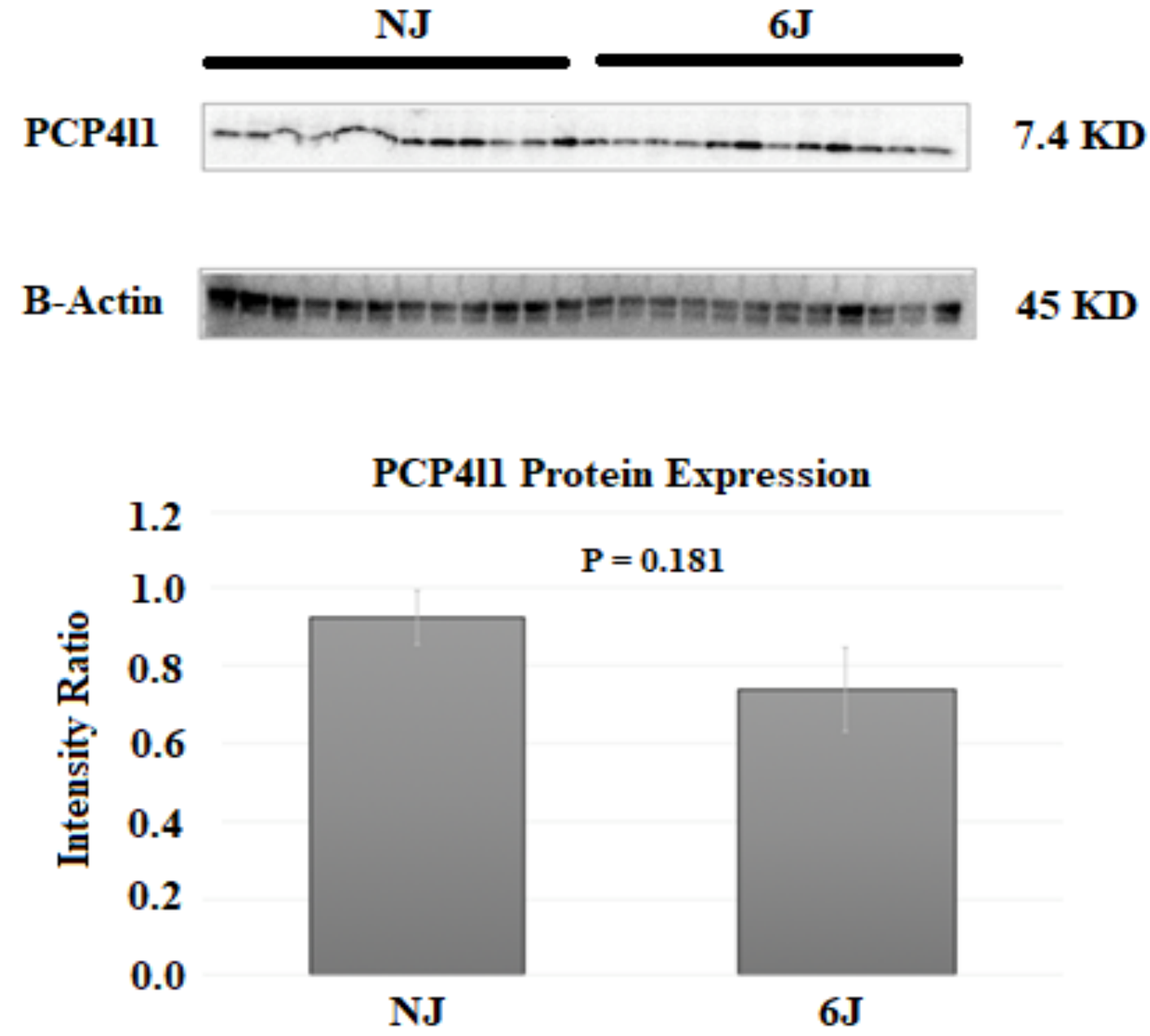
Figure 7

NJ

6J

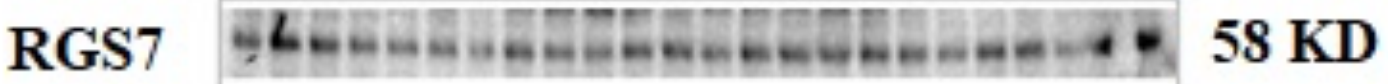

B-Actin -

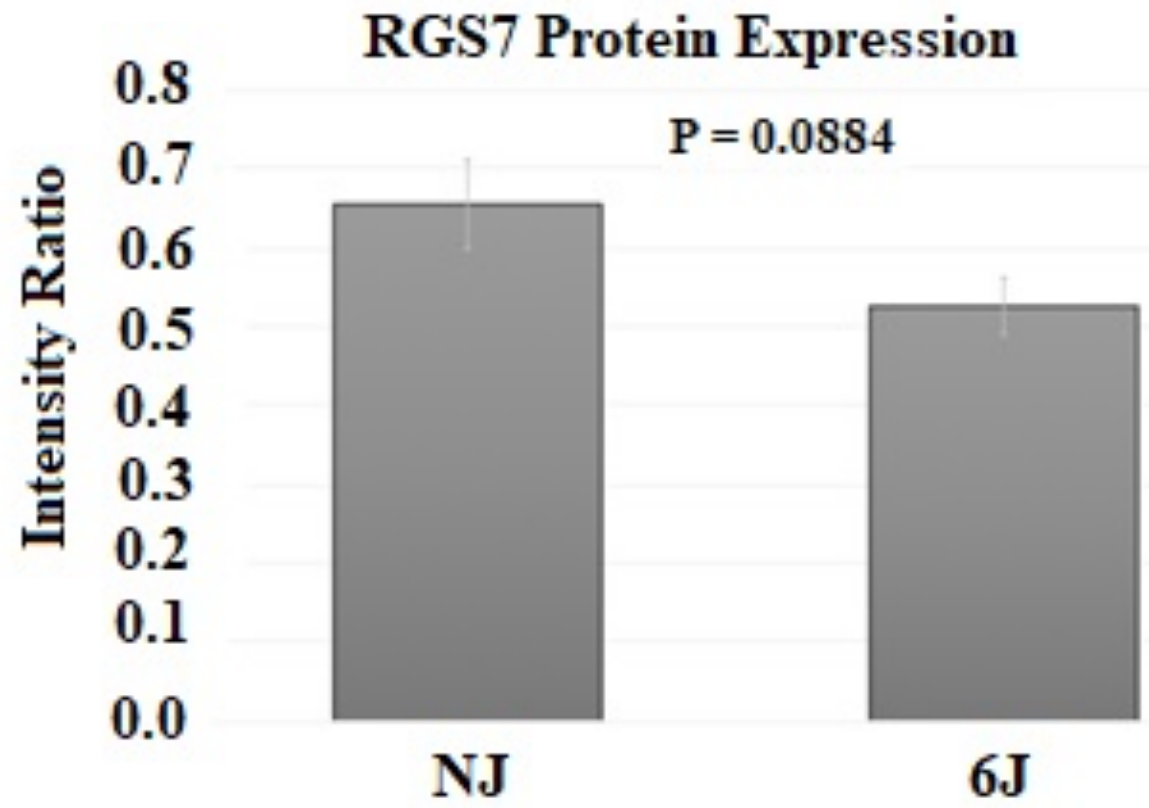


Figure 8

NJ

6J

CADM3

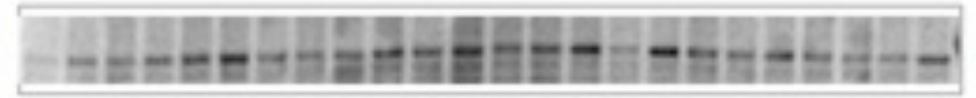

$43 \mathrm{KD}$

Molecular Weight $=43 \mathrm{kD}$

B-Actin

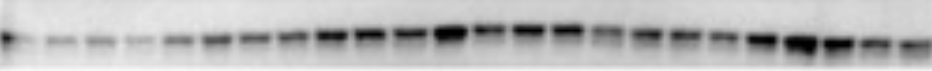

$45 \mathrm{KD}$

CADM3 Protein Expression

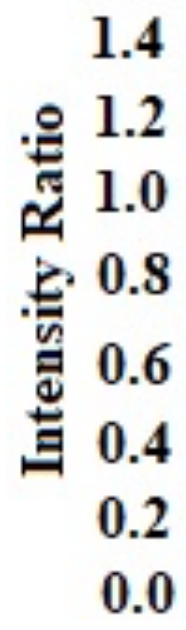

$$
P=0.162
$$

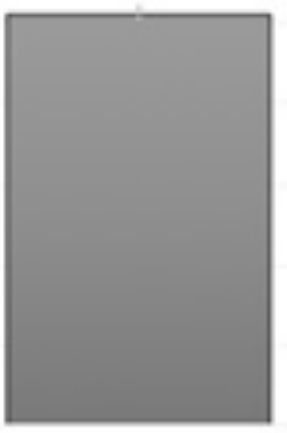

NJ

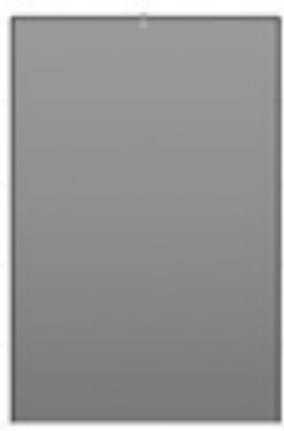

6J 
Figure 9

NJ

6J

IGSF8

$64 \mathrm{KD}$

B-Actin - -

IGSF8 Protein Expression

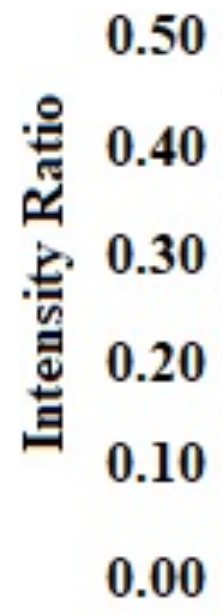

$P=0.329$

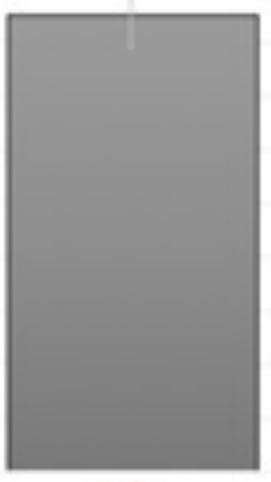

NJ

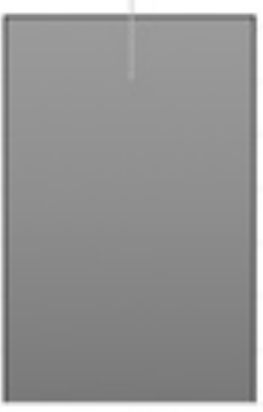

6J 